\title{
Escutar no Som: gravação e edição de etnografias sonoras a partir de um paradigma ecológico
}

\author{
Viviane Vedana \\ Universidade Federal de Santa Catarina, Florianópolis, Santa Catarina, Brasil \\ E-mail: viviane.vedana@ufsc.br
}




\section{Resumo}

Discuto neste texto o som a partir da perspectiva ecológica. Trata-se de uma compreensão antropológica das sonoridades como entes em um conjunto de relações e de interações, mais do que simples dados ou aspectos da paisagem. Argumento que os processos de gravação e de edição de sons não são meras reproduções do real, mas formas de aproximação específicas aos sistemas de percepçãoação que compõem as paisagens estudadas. Sigo ainda a discussão sobre a etnografia como transdução para pensar como gravação e edição operam nessas aproximações aos sistemas perceptivos com os quais nos deparamos em campo. A ideia de escuta no som é aqui entendida como uma forma de educação da atenção ou de descoberta orientada para a produção de registros sonoros em campo, tendo em vista o argumento da transdução como forma de fazer etnografias sonoras.

Palavras-chave: Som. Etnografia. Paradigma Ecológico. Transdução.

\section{Abstract}

I discuss in this text the sound from the ecological perspective. It is an anthropological understanding of sonorities as entities in a set of relationships and interactions rather than simple data or aspects of the landscape. I argue that the processes of recording and editing sounds are not merely reproductions of the real, but specific approaches to the perceptionaction systems that compose the landscapes studied. I still follow the discussion about ethnography as a transduction to think how recording and editing work in these approaches to the perceptual systems that we come across in the field. The idea of listening in sound is understood here as a way of education of attention or discovery oriented to the production of sound records in the field, considering the argument of transduction as a way of making sound ethnographies.

Keywords:Sound. Ethnography. Ecological Paradigm. Transduction. 


\section{Introdução}

Dregões de preços e qualidade dos alimentos, risadas, jocosidades, 1 piadas, conversas, negociações, combinados com uma série de outros "ruídos" dos gestos de fazer a feira (puxar carrinhos, escolher alimentos, trocar dinheiro, montar e abastecer banca, etc.) configuram o ambiente da feira livre e foram alguns dos elementos fundamentais da minha compreensão do mercado como um evento ou acontecimento (Vedana, 2008; 2013; 2017). A discussão sobre as socialidades e a circulação da palavra entre fregueses e feirantes, sobre as aprendizagens e sobre o trabalho passou necessariamente por uma atenção ao som e a um engajamento com a etnografia destes sons: como apresentavam as dinâmicas do mercado, seus horários de pico ou de pouco movimento, como indicavam determinados ritmos do trabalho ao mesmo tempo em que informavam sobre os gestos e técnicas corporais dos sujeitos que, junto com outros objetos e coisas faziam emergir o mercado.

A discussão que gostaria de propor neste texto diz respeito às possibilidades e às perspectivas de um tratamento antropológico para o som, nos moldes do que aponta Steven Feld em Doing Anthropology in Sound (2004). Feld enfatiza a necessária atenção para a materialidade e sociabilidade dos sons em um determinado contexto de interação (como os lugares soam? Como descrever sons nas etnografias? O que as sonoridades revelam?) e, nesse sentido, procuro pensar em como transformar essa atenção em narrativas etnográficas. Assim, vou chamar de "etnografia sonora" os processos de gravação e edição de sonoridades das práticas cotidianas, das paisagens e socialidades compartilhadas em campo, bem como os produtos que resultam destes processos - paisagens sonoras, documentários, etc. Para isso, irei 
fazer referência há algumas experiências de pesquisa que possibilitem melhor compreender o argumento. Entre essas experiências destaco as etnografias que realizei em feiras-livres (Vedana, 2004; 2008) e minha participação na pesquisa a respeito da pesca da Tainha na Barra da Lagoa, em Florianópolis (Devos; Barbosa; Vedana, 2015; 2016). Além disso, ao longo do texto farei referência ao material audiovisual que foi elaborado nestas pesquisas por meio de links que conduzem a sua visualização online. São vídeos e paisagens sonoras cuja captação de som direto e edição de som foram realizadas por mim (Vedana, 2011). Em alguns casos também editei as imagens visuais, mas, de maneira geral, a edição das imagens visuais foi realizada por Rafael Devos ${ }^{1}$.

Proponho discutir como a perspectiva ecológica - proposta por Tim Ingold (2000; 2011), inspirado em James Gibson (1979) - pode ser interessante para compreender o som como parte das relações inscritas no ambiente, mais do que um dado ou aspecto da paisagem, ou ainda como um efeito de representação do real a partir de seu registro e edição. Essa perspectiva nos propõe soluções para as críticas de Michel Chion (1998), compositor de música experimental e pesquisador da relação audiovisual, às abordagens que veiculam o som como mero produto de suas fontes sonoras. Chion é enfático ao afirmar que som e fonte sonora são elementos diferentes de um mesmo processo e que, ao estudarmos os sons, deveríamos atentar para as suas dinâmicas, ritmos, movimento e formas de expressão. Essa crítica, que pressupõe uma reflexão técnica sobre o som, se aproxima às analises de Tim Ingold $(2000 ; 2011)$ a respeito do som enquanto um meio por meio do qual podemos escutar.

Falar de som nos convoca necessariamente a pensar sobre a escuta. Para Feld (1996; 2015), tanto ouvir como produzir sons são competências incorporadas a partir da experiência, de engajamentos perceptivos num ambiente e que podem ser pensadas em termos de uma acustemologia - uma epistemologia acústica que trata das condições locais de sensação sonora, e que revela um senso particular de lugar. Já Tim Ingold (2010) vai argumentar que as formas de conhecer ( sejam elas relacionadas à escuta e ao som ou não) seriam habilidades desenvolvidas a partir desse engajamento prático com o ambiente, mais 
do que competências incorporadas. Considerando esses argumentos, minha proposta é refletir sobre o som e a escuta como processos em constante produção, e que nos permitem aproximações particulares às práticas e sociabilidades que observamos em campo.

Tendo em vista que tomo aqui o som como uma presença (Feld, 1996, p. 92) e como uma diferença (Bateson, 1986, p. 121; Bateson, 1987, p. 312) que possibilita a escuta, gostaria de refletir sobre os processos de engajamento no ambiente que favorecem a transdução das sonoridades da paisagem para registros sonoros e para narrativas etnográficas, realizando então a "antropologia em som" que nos demanda Feld (2004). Gravação, montagem e edição, nesse caso, não estão relacionadas a uma representação ou reprodução do real, mas a aproximações e transformações das dinâmicas das relações vividas (em campo) para outro meio (a narrativa, o documentário). Aproprio-me da discussão de Helmreich (2016) sobre a etnografia como transdução para pensar os registros sonoros, bem como as montagens, como processos de transdução ${ }^{2}$. A pergunta que subjaz ao argumento da etnografia como transdução se refere aos modos de atenção que questionam os sentidos que emergem das relações materiais entre objetos e pessoas (por exemplo) e que não podem ser formuladas com antecedência, ou fora dessas relações materiais que se estabelecem em campo. Podemos reformular essa preocupação se nos perguntarmos como aprendemos e descobrimos as práticas, as paisagens, os gestos e os saberes de nossos companheiros de pesquisa ao realizar registros sonoros (ou fotográficos, videográficos, etc.)? Além disso, como acontece (ou o que acontece) a reorganização desses registros na montagem e edição de narrativas etnográficas? Esaas são algumas das questões sobre as quais busco refletir neste texto.

\section{Uma Perspectiva Ecológica para o Som?}

A abordagem ecológica da ação e da percepção proposta por James Gibson (1979) está ancorada no pressuposto de que objetos e eventos existem em uma relação ecológica, sendo percebidos, portanto, a partir dessa relação. Pessoas, objetos, eventos tem assim uma existência relacional enquanto uma presença no ambiente, enquanto um evento 
ecológico que não é mera representação. Essa existência passa a ser especificada por processos de percepção direta - ou não mediada por processos cognitivos - de informações sobre as propriedades dos objetos, eventos e superfícies que conformam um determinado ambiente. O que se entende por informação seriam padrões de energia estruturada pelo ambiente -padrões de energia sonora, padrões de energia luminosa que informam sobre eventos, objetos, movimentos, texturas, cores, ritmos. Um exemplo sempre recuperado da obra do autor para exemplificar essa ideia seria a diferença observada por Gibson (1966) entre luz radiante e luz ambiente, sendo a primeira os conjuntos de raios luminosos originários de diversas fontes de energia que irradiam pelo espaço e que são percebidas pelo observador em termos de quantidade de energia (mais luz, menos luz). Já a luz ambiente seria aquela refletida pelas superfícies e objetos que modificam a luz radiante, estruturando essa energia de maneiras específicas e informando o observador sobre a forma, textura, tamanho dos objetos. Essa luz ambiente, por ser refletida e estruturada pelos objetos, torna-se então informação sobre estes, ou seja, é diretamente percebida pelo observador como as características das coisas que conformam um dado ambiente. Isso é possível, segundo Gibson, pois parte dessa energia estruturada pelo ambiente é invariante ${ }^{3}$, mesmo que o observador esteja em movimento.

O movimento é aqui fundamental, pois dele depende a percepção: ou seja, é o movimento - seja ele do deslocamento no espaço, seja o movimento da cabeça ao olhar/escutar ao redor, ou mesmo dos olhos - que possibilita ao observador perceber as variações no ambiente, as informações que especificam cores, formas, distâncias, texturas, temporalidades, etc. É nesse sentido que percepção e ação são compreendidas como processos interdependentes - agir é perceber e vice-versa.

[...] when I assert that perception of the environment is direct, I mean that it is not mediated by retinal pictures, neural pictures, or mental pictures. Direct perception is the activity of getting information from the ambiente array of light. (Gibson, 1979, p. 147) 
Perceber constitui-se numa relação mútua e recíproca entre organismo e ambiente - o organismo percebe para agir e age para perceber (Fonseca et al. 2007), trata-se de uma exploração ativa do ambiente, e não apenas recepção passiva de estímulos. Costumava ouvir de Akli, um feirante do Marché Maubert em Paris onde realizei etnografia, que os arranjos da banca de frutas, temperos, legumes, verduras era um elemento fundamental do sucesso de suas vendas ou, melhor ainda, da efetividade de seus laços com seus clientes (https:// vimeo.com/68260005). Essa mesma perspectiva era compartilhada por Henrique, feirante do Mercadão do Produtor em Porto Alegre (https://vimeo.com/68324096). A banca com suas cores e formas devia atrair o olhar dos fregueses, chamar atenção. As formas como estes mercados eram organizados no espaço da cidade, e mesmo as suas dinâmicas de oferta e venda de alimentos guardavam diferenças entre si: em Porto Alegre o Mercadão do Produtor ocupava um espaço grande no Largo Zumbi dos Palmares, enquanto o Marché Maubert ocupava uma pequena praça em Paris; no primeiro caso cada feirante ou banca se especializava em um ou dois produtos, seguindo um certa classificação, já no segundo, cada banca poderia oferecer uma variedade maior de alimentos. Essas diferenças, no entanto, não suplantavam as similaridades que se apresentavam de um lado na intensa paisagem sonora desses mercados e de outro na preocupação com o arranjo das bancas e a relação com os fregueses (Vedana, 2008). Esse arranjo precisava ser refeito ao longo de todo o período da feira-livre, conforme as compras aconteciam (Vedana, 2008) e a quantidade de produtos na banca diminuía. O ritmo de trabalho dos feirantes, no entanto, não permitia "uma parada" para repensar essa composição e o que observei em campo foi justamente a habilidade tanto de perceber a falta de produtos na banca bem como a "bagunça" deixada pelos inúmeros clientes e rearranjar esse quadro formado pela banca numa sequência de gestos incorporados ao próprio ato de vender. Era no movimento de se deslocar pela banca e realizar suas vendas que os feirantes percebiam as formas que a banca tomava e a remodelavam constantemente (Vedana, 2017). 
Dessa perspectiva, e pensando ainda a partir do interior de um mercado, podemos nos perguntar, tal qual Gaver (1993) se pergunta a partir das análises de Gibson: o que o som faz/possibilita? Quais as dimensões e características dos eventos que se obtém por meio da escuta? Em termos das experiências etnográficas, essa perspectiva ecológica da percepção sonora nos orienta a ter em conta que o som não é apenas um conjunto de ruídos que fazem parte compulsoriamente de eventos ou cenas das quais participamos, mas são indícios de interações e ações específicas, com desdobramentos temporais e espaciais que nos informam sobre as dinâmicas estudadas. Trata-se concretamente de uma forma de atenção e de conhecimento do ambiente.

Na experiência de habitar o mercado, seja para feirantes seja para fregueses (e sem dúvida para a pesquisadora) a ambiência sonora é parte importante das formas de conhecer suas dinâmicas. A presença dos mercados que estudei nos contextos urbanos em que estavam inseridos podia ser percebida ainda a certa distância nos arredores do bairro. Conforme nos aproximávamos, indícios de que da existência do mercado se mostravam no som das sacolas ou carrinhos de feira arrastados pelas ruas, mas principalmente nas vozes anunciando seus produtos que se escutava ao longe. Chegando ao mercado - ou nestes mercados em particular - éramos capturados por sua ambiência, seja pela intensidade da circulação da palavra, seja pela exuberância das bancas e dos alimentos. Como podemos, a partir da abordagem ecológica de Gibson, identificar as peculiaridades do som na composição do mercado? Para Gaver, a energia sonora também é estruturada pelo ambiente e assim o especifica, de forma que guia a ação de quem escuta, ou melhor, fornece informações a respeito dos eventos sonoros e suas fontes, bem como do ambiente e seus elementos. Uma abordagem ecológica para o som não está preocupada - ou não apenas - com as características de altura, timbre e intensidade, mas sim em como essas caraterísticas são estruturadas pelo ambiente e, por isso mesmo, informam sobre o os elementos e eventos que o compõem. Para Gaver, o que ouvimos são eventos sonoros decorrente de interações entre materiais que se caracterizam por forças exercidas em sólidos, líquidos e gases, força que gera vibração e leva os objetos a soar. Não pretendo 
me deter aqui na discussão proposta pelo autor sobre os diferentes meios de propagação da energia sonora e suas diferenças, mas busco situar seu argumento central de que há um continuum de energia entre o "evento fonte" e a experiência de escuta. As forças exercidas sobre os objetos - tocar, bater, perfurar, raspar, esfregar, roçar, friccionar, rolar, vibrar - os retiram de seu estado de equilíbrio, "deformando sua configuração original" (Gaver, 1993) e informando os processos auditivos. O ambiente do mercado é formado por um conjunto de materiais com potencialidades sonoras - as bancas de madeira, as lonas e sacolas plásticas, os próprios alimentos, as vozes, os carrinhos de metal ou mesmo de lona que carregam alimentos, materiais que quando em interação constituem uma paisagem específica.

Tim Ingold também se inspira nas formulações de Gibson (1979) sobre a percepção em seu debate sobre organismo engajado no ambiente buscando superar as clássicas divisões entre corpo e mente, ação e pensamento e mesmo organismo e ambiente como se fossem entidades separadas, para pensá-los como processos interdependentes. Sua proposta é seguir interações entre humanos, não humanos e ambiente com ênfase na prática, nos sistemas perceptivos e no desenvolvimento de habilidades que são constantemente desenvolvidas ao longo da vida. Remeto-me aqui diretamente aos saberes e fazeres que fazem emergir os mercados: se de um lado temos a composição da banca pelos feirantes e sua habilidade de elaborar uma composição estética para a banca de frutas, conforme apontei acima, de outro podemos observar os conjuntos de gestos que são acionados pelos fregueses na escolha dos alimentos que irão comprar. Os cheiros, texturas, cores, o gosto e mesmo o som dos alimentos (https://vimeo.com/68262941) orientam os fregueses nesta escolha: a mão que testa a consistência de uma fruta, o frescor de sua casca, o tamanho, o olhos que rapidamente identificam se existem partes machucadas ou amassadas, que verificam a cor, o ouvido atento ao som do maracujá que é chacoalhado para se identificar como está o interior da fruta, tudo isso em poucos segundos. Mãos, olhos, ouvidos não agem separadamente, mas conjuntamente, ou como diria Gibson, solidariamente na percepção das frutas a serem escolhidas. Isso não significa dizer que se trata de um saber intuitivo, 
mas sim que esses engajamentos se deram inúmeras vezes no interior do mercado, ao ponto de se tornarem uma habilidade de todo o corpo e não apenas uma classificação mental (ou cerebral) dos alimentos.

A escuta pode ser pensada, portando, como uma habilidade a ser desenvolvida, como parte de um sistema que envolve os ouvidos, a cabeça, o corpo em movimento e os eventos ou interações entre materiais que produzem energia sonora, de tal forma que a percepção auditiva (Gibson, 1966) nos possibilita conhecer um determinado ambiente e seus acontecimentos. Na paisagem do mercado, a atenção aos sons é um aspecto da inserção de feirantes e fregueses num certo ritmo das práticas de compra e venda, de conversação e de trabalho. Como descrevo em outro artigo (Vedana, 2017), os ritmos do trabalho (https://soundcloud.com/vi-vedana/ritmos-do-trabalho) são marcados pelos sons das vozes que anunciam produtos e ao mesmo tempo orquestram as relações no interior da banca. Atender aos clientes, estar atento para a reposição dos produtos e anunciar o que está à venda são atividades marcadas por sequências de gestos que, em correspondência com os gestos e a atenção dos fregueses, fazem o mercado acontecer e informam sobre suas dinâmicas para todos que ali estão engajados. Os sistemas perceptivos - audição, visão, etc. - estão assim articulados nas práticas de fazer o mercado e seu desdobramento em gestos e ações pode ser observado como um sistema de informações ou sinais que marcam os diferentes momentos do mercado: a montagem das bancas, o início das vendas, o período de maior movimento, bem como o encerramento das atividades (Vedana, 2017).

\section{Descobrindo Sons}

É cedo na praia da Barra da Lagoa em Florianópolis/SC, o sol começa a nascer e um vento frio e constante vem do sul. No microfone, escuto um ruído intenso e fico me perguntando como é possível "gravar" a perturbação desse vento na paisagem. Não bastasse sua insistência em "bater" no microfone, causando um ruído desagradável e difícil de identificar, as ondas fortes que arrebentam na praia também se sobrepõem às conversas dos vigias que já olham atentos ao mar. Sinto a 
areia ser carregada pelo vento rente ao chão e imagino que elas podem ser também sonoras. Me abaixo e concentro a atenção e direção do microfone para a passagem do vento-areia, descubro aí uma das formas do vento sul, a da areia que corre na praia. Não sei se quando ouvir novamente esse som, aí então gravado, vou ter a mesma sensação, ou se será possível identificar essa peculiaridade da paisagem da Barra da Lagoa em meados de maio, outono, com vento sul e quase sem pessoas na beira da praia, mas aprendo que há sinais e informações nesse ambiente que são muito diferentes daqueles que ouvi nos mercados e estudei e sobretudo percebo que o sistema "pesquisador-microfonegravador-ambiente" opera aqui de maneiras distintas. As informações e sinais percebidos na espera pelos cardumes de peixes informam sobre uma paisagem particular e demandam outros movimentos corporais na direção da "captura" dos sons. O que pode ser óbvio, ou seja, outra experiência etnográfica, logo outra experiência de gravação, revela os processos de educação da atenção (Ingold, 2010) que o trabalho de campo nos proporciona. O registro sonoro não é apenas uma técnica a ser aplicada em qualquer espaço do mesmo jeito, pois os padrões de transformação e diferença de cada ambiente também mudam.

Tim Ingold argumenta que esses padrões de informação que estão em jogo na relação organismo-ambiente constituem um processo de "descoberta orientada" que permitem conhecer - a paisagem, o ambiente, as formas de relação, o eventos, etc. a partir das formas de se relacionar com as coisas (Ingold, 2012). No caso dos sons, podemos pensar nos ritmos, nas intensidades, nas interações entre materiais e suas vibrações que produzem diferenças em uma dada paisagem e que possibilitam identificar e mesmo prever acontecimentos. Em termos do contexto etnográfico da pesca da tainha na Barra da Lagoa em Florianópolis/SC (https://vimeo.com/251 143157), onde acompanhamos ${ }^{4}$ vigias em sua tarefa de identificar cardumes no mar e orientar os pescadores sobre como fazer o cerco, eram justamente esses sinais da paisagem - mudanças de ventos e marés, a presença ou não de pássaros, os brilhos na água - que constituíam-se como indícios dos peixes para os camaradas da pesca. Suas práticas e gestos - uma espera longa e por vezes monótona, entrecortada com conversas, risadas e 
cafés, ou então a agitação e correria na beira da praia, orientando o cerco - relacionadas a olhar atentamente para o mar, observar suas sutis diferenças, perceber o vento, eram para nós o indício de habilidades desenvolvidas ao longo do tempo e orientavam nossas formas de estar junto, observando a paisagem e, sobretudo, "gravando".

Considerando as reflexões de Bateson sobre os sistemas mentais que extrapolam a concepção de uma mente que pensa e oferece as coordenadas para a ação do corpo para argumentar em termos de um sistema de comunicação que age por diferença (Bateson, 1986, p. 104) a partir da interação entre suas partes, podemos pensar os processos comunicativos que ocorrem nesse contexto da pesca da tainha, na Barra da Lagoa. A ideia de sistema pode oferecer algumas vantagens para analisar as percepções e ações que estão em jogo no momento do cerco dos cardumes, por exemplo, pois nos permitem observar e descrever o que fazem os pescadores, mas também o que faz a rede, a canoa, os peixes, etc. Um momento significativo deste circuito de informação que constitui um sistema de comunicação (nos termos de Bateson) é o momento final do cerco dos peixes em que os pescadores na praia precisam "puxar a rede" e completar a captura das tainhas. Um conjunto de diferenças na paisagem da praia se impõe por meio da voz de quem comanda o cerco que, combinada com a ritmicidade das ondas, a intensidade dos ventos e a força exercida pela rede, informa sobre o ritmo do movimento dos camaradas para puxar a rede. Não se trata de um código a ser decifrado, mas de certo estado de atenção a estas transformações que se desdobram em ações de puxar com mais força, fechar a rede, "baixar o chumbo" (segurar com o pé a parte de baixo da rede), entre outros movimentos. Neste momento, pescadores e camaradas da pesca, as ondas do mar, a rede e mesmo as tainhas, além é claro do comando vocal do patrão da parelha conformam um sistema de comunicação que se encerra com os peixes fora da água, na areia.

A experiência etnográfica também poderia ser pensada como uma descoberta orientada - pelo ambiente, pelas diferentes práticas, pelos animais humanos e não humanos e no caso deste texto, também pelo equipamento de gravação que, junto com o pesquisador, conforma um sistema (microfone - gravador - pesquisador - ambiente/práticas/ 
interlocutores, etc.). É nesse sistema de "aquisição de pistas" sobre o que se passa em campo, sobre os eventos que buscamos etnografar, que podemos nos engajar para propor narrativas sonoras etnográficas - uma forma de apreender os ritmos, os movimentos, as práticas e técnicas que falam dessa experiência particular de tempo e espaço. O som, nesse caso, é uma das pistas de revelação do mundo: podemos conhecer as socialidades nos mercados de rua por meio da atenção à circulação da palavra entre feirantes e fregueses (Vedana, 2008); ou saber sobre as formas de ver peixe e os ritmos das práticas de pesca, atentando as sonoridades da paisagem (Devos; Barbosa; Vedana, 2017). Se a etnografia no mercado nos informa sobre as práticas e habilidades de fregueses e feirantes na sua relação com os alimentos ou na construção de sociabilidades (Vedana, 2013), a etnografia sobre ver peixe na beira da praia nos desafia a escutar as sutis transformações na paisagem efetivadas pelas subidas e descidas das marés, pelo ritmo das ondas, pelo sopro do vento, mas também pela intensidade das trocas verbais entre pescadores e vigias que se comunicam por telefone ou pelo rádio para trocarem impressões ao longo do dia. Todas essas mudanças informam também sobre a presença ou não das tainhas no mar e a possibilidade de captura pelos pescadores.

O trabalho de campo, nesse caso, consiste em aprender a ver peixe, a fazer a feira, a entender as dinâmicas de determinados sistemas de comunicação. Aprender a ver peixe ou a fazer a feira não significa apreender conceitualmente (apenas), mas seguir os processos perceptivos que o sistema microfone - gravador - pesquisador - ambiente - práticas interlocutores pode nos proporcionar, descobrindo suas particularidades também por meio do som. Isso envolve necessariamente uma atenção especial à escuta. Seguindo as proposições de uma ecologia da vida, proposta por Ingold (2008, p. 3), som é escuta:

[...] o que dizemos escutar, ao menos quando falamos sobre estes assuntos, é o bater de uma porta, o assobio do vento, o zumbido ou a explosão do motor do carro e o ruído da locomotiva. Estrondear, assobiar, zumbir, entre outras, são palavras que não descrevem coisas, mas ações ou movimentos, os quais, devido às vibrações que causam, na verdade sentimos como barulhos de diferentes tipos. 
Uma crítica similar é elaborada por Michel Chion (1998) ao refletir sobre as narrativas sonoras no cinema, nas quais o som é muitas vezes tomado como um enxerto para a narrativa visual. Para Chion o som é sempre produzido a partir de uma ação ou intenção e, como padrão vibratório, deve ser compreendido como movimento e como tempo. Ingold também compreende o som como movimento e fluxo - como séries de inter-relações rítmicas de padrões de ressonância do ambiente. É um meio que possibilita a escuta, assim como a luz é o meio que possibilita a visão - são affordances que orientam a ação. Embora o conceito de affordance não tenha uma tradução exata para a língua portuguesa, seu sentido pode ser elaborado em termos daquilo que os objetos, espaços ou entes propiciam à ação. Podemos pensar nas frutas na banca da feira-livre que rementem ao gesto de pegar, agarrar, ou ao exemplo dos degraus de uma escada que rementem a ação de subir ou mesmo sentar. Affordances também podem ser pensadas como relações dos seres com as coisas - na abordagem de Ingold e mesmo Gibson não está restrito aos humanos - que se efetivam em gestos. $\mathrm{O}$ som, dessa perspectiva, é uma possibilidade de escuta. Dessa forma, a experiência etnográfica nos demanda uma atenção à vibração, aos ritmos, à ressonância que fazem parte do processo de escuta, ou da escuta e do som engajados.

Esse argumento pode ainda ser avançado tomando-se em conta o que Steven Feld (1996, p. 92) afirma em Waterfalls of song: an acoustemology of place resounding in Bosavi, Papua New Guinea: o que a percepção nos dá são presenças e não verdades - a presença dos corpos sensuais e perceptivos em interação. Segundo o autor a experiência não é sempre sublimada para a abstração, mas as sensações são sempre experiências de presença e que podem ressoar em formas de agir ou sentir, ou se relacionar com as coisas. Para Feld o corpo é central nessas abordagens, pois é onde se apresentam as variações e diferenças que promovem a percepção. O som, assim, é uma condição para o conhecimento, há um potencial acústico do conhecimento que no caso de suas pesquisas, acaba se traduzindo em formas de andar pela floresta e reconhecer suas propriedades, além também de se expressar em canções. Assim, a exploração das sensibilidades sonoras presentes em determinados 
contextos refere-se à descoberta das experiências de espaço e tempo por meio do som, na qual o espaço indexa a distribuição do som enquanto o tempo indexa o seu movimento.

\section{4 "Escutar no Som" e Etnografia Sonora}

Em outro texto (Vedana, 2017) procurei argumentar sobre a correspondência entre as sonoridades do mercado, sobretudo os atos de fala dos feirantes, com suas técnicas corporais e os ritmos do trabalho que desenvolvem durante as vendas. Esse argumento decorre do engajamento corporal no registro sonoro no interior das bancas do mercado, da busca por escutar não apenas as palavras que estavam sendo ditas, mas escutar "nelas" para perceber o que esses atos de fala informam sobre os movimentos, gestos e práticas no interior de uma banca de feira-livre - não qualquer banca, mas aquelas especificamente que me comunicavam a emergência ali de certo sistema de informações que fazia o trabalho funcionar de maneira mais eficaz. Anunciar o preço de um produto, organizar os alimentos na banca, conversar com fregueses, pesar as compras, receber o pagamento, fazer o troco, reabastecer a banca são ações que se repetem ao longo de um dia de feira, simultaneamente ou concomitantemente, por vários feirantes no interior de uma mesma banca. Ações que derivam umas das outras e assim constituem sistemas comunicativos que "fazem a feira" emergir.

A descoberta desses ritmos de trabalho parte fundamentalmente da atenção ao som, sobretudo de uma atenção de certa forma mediada pelas tecnologias de registro sonoro que pude experimentar nos mercados de rua em que pesquisei, mercados sonoramente muito expressivos, com grande diversidade de feirantes, fregueses, alimentos, gestos e práticas. A etnografia sonora no mercado consistiu em seguir essas ações e sonoridades, fazendo o registro sonoro adotar ou participar da candência dos movimentos da banca, por meio de aproximações ou afastamentos dos gestos ou ações dos feirantes, tendo em vista esta comunicação dos atos de fala ou de suas técnicas corporais. É importante ter em conta que essa percepção das socialidades do mercado (Vedana, 2013) por meio dos sons não é definida pela realização da etnografia, mas está concretamente operando no cotidiano do mercado, na medida em 
que os sujeitos que produzem estes ritmos - seja na fala, seja em seus gestos, normalmente as duas coisas ao mesmo tempo - estão "sendo" feirantes ou fregueses justamente por se engajarem nesses processos comunicativos, ou seja, por fazê-los acontecer. Outra consideração a se ressaltar é que não estou afirmando que há uma anterioridade dos atos de fala na produção de um ritmo dos gestos de trabalho. Aponto, isto sim, para uma combinação entre corpo - movimento - fala que faz emergir o mercado (Vedana, 2017). Minha hipótese aqui é que essa combinação se explicita tanto na escuta e registro sonoro em campo, como na escuta e posterior montagem - na forma de narrativas, documentários, etc. - desses sons gravados em campo.

A partir dessa mesma perspectiva poderíamos pensar o ver peixe pelos vigias da pesca da Tainha na Barra da Lagoa/SC e, sobretudo, o momento do arrasto da rede após a captura do peixes no mar. Como discutido em outros textos (Devos; Barbosa; Vedana, 2015; 2016), a prática de "ver peixe" pelos vigias da pesca da Tainha em Florianópolis não consiste em "enxergar" o peixe ou os cardumes na água, mas estar atento a conjuntos de transformações na paisagem que indicam a presença da tainha. Transformações na direção e intensidade dos ventos, mudanças no comportamento dos pássaros, subidas e descidas das marés, estão entre as alterações na paisagem da praia que informam aos pescadores e vigias a presença do peixe. A atenção desses vigias, portanto, não é apenas visual, mas também auditiva, tátil, háptica. Conforme Gibson (1979), os sentidos são inter-relacionados e não exclusivos, ou seja, cooperam para a percepção. Nesse caso, mais do que canais de transmissão de qualidades sensórias, trata-se de sistemas ou o que Gibson chamou de "modos de atenção" que se desenvolvem como habilidades perceptivas a partir de diferentes interações e experiências com pessoas, animais, objetos, coisas, enfim com o ambiente. A habilidade do vigia da pesca da tainha em ver peixe não só ver como também estimar a quantidade e a direção do movimento do cardume - é desenvolvida na prática de observar as mudanças na paisagem. Assim, uma etnografia sonora precisa se aproximar, ou melhor, se corresponder com essas mudanças, considerando que o registro dessas sonoridades - e também sua posterior edição em 
narrativas - poderia reapresentar as nuances e especificidades dessa paisagem e da prática de ver peixe, nos moldes da descrição que abre um dos subtítulos deste texto e que trata sobre a gravação do vento sul.

Compreender a percepção como o engajamento do corpo-organismo no ambiente significa extrapolar a compreensão da escuta como um privilégio dos ouvidos para ser pensada como um processo de todo o corpo, que envolve os demais sistemas perceptivos (segundo Gibson: o sistema básico de orientação, o sistema auditivo, o sistema háptico, o sistema olfato-gustativo, o sistema visual). Em seus estudos sobre os Kamayurá, Bastos (1999) refere-se à escuta como ao mesmo tempo ativa e passiva, pois para o grupo em questão ouvir é receber sons do ambiente e ao mesmo tempo captá-los pelo ouvido. Ao andarem pela floresta, os Kamayurá percebem grande número de informações sonoroauditivas (Bastos, 1999) de diferentes direções; realizam movimentos sonoros para se comunicarem com seus companheiros, animais ou espíritos. Em suas conversas diárias, apresentam rico repertório lexical fonoauditivo e sonoro e consideram fundamental se referir de maneira hábil aos sons. Considerando aspectos como esses de sua experiência etnográfica, o autor propõe um estudo de antropologia da percepção como antropologia do corpo, argumentando que os contextos de socialização dos sujeitos - ou seja, suas experiências cotidianas tendem a acentuar determinados sistemas perceptivos em detrimento de outros, criando assim o que denominou axionomia (Bastos, 1999b, p. 87), uma espécie de classificação valorativa dos sentidos que se reflete de forma contundente na comunicação e na elaboração de conceitos e categorias pelos sujeitos. É a partir daí que formula a ideia de world hearing (1999b, p. 87), ou seja, observa que há, entre os kamayurá ao menos, uma concepção de mundo orientada pela escuta em detrimento de uma "cultura visual" que tenderia a predominar em sociedades ocidentais modernas. Embora a perspectiva que adoto neste texto não avança no sentido de classificar os sistemas perceptivos em níveis ou graus de relevância - sobretudo porque são interdependentes no processo perceptivo - análises como esta me parecem fundamentais, pois nos fornecem caminhos que nos deslocam dos sentidos comuns de entendimento do som e da escuta na antropologia, normalmente 
pouco considerados fora dos contextos mais específicos do estudo da música e da musicologia.

A questão que podemos colocar ao refletir sobre world hearing é a de que ouvir - ou escutar - é um aprendizado que envolve experiências cotidianas de observação e atenção aos sons, não um mecanismo prédeterminado de estímulo-resposta. Daniel Deshays (2006), compositor e engenheiro de som que produz composições para o teatro, também concebe a escuta nesses termos, para ele a escuta é desejante e se nutre de uma "errância" atenta ao entorno. Nesse caso, todo o corpo é tocado pelo que atravessa nossos ouvidos e todo o ser se engaja nessa escuta. Escutamos com o corpo, não com os ouvidos apenas. É necessário considerar aqui a longa discussão que se estabelece em diversas áreas na filosofia, na música, nas artes, etc. - sobre a diferença entre hearing e listening, ou entre ouvir e escutar. Basicamente os primeiros termos - hearing e ouvir - são identificados como uma dimensão passiva da percepção sonora, com o fato de que ouvimos ou percebemos sons mesmo sem compreender ou sem desejar ouvir, enquanto listening e escutar seriam compreendidos como uma espécie de escolha ou com um esforço consciente de atenção e escuta. Não vou desenvolver de forma aprofundada esse tema aqui, mas um dos pressupostos que conduz a esse debate está relacionado à separação entre um processo biofisiológico da escuta, o qual não podemos controlar, e um processo cognitivo-intelectual de busca de compreensão pela atenção aos sons geralmente a discussão sobre este último ponto se refere a compreensão do discurso e das palavras que são proferidas por um interlocutor. James Gibson de certa forma também está atendo a essa diferença, porém sua questão central em relação ao sistema auditivo é em primeiro lugar de que não se trata de um processo perceptivo isolado de outros - como a visão, tato, etc. - e em segundo, que a função desse sistema não é simplesmente permitir a escuta, mas captar a direção de um evento, possibilitando assim a orientação de quem escuta até esse evento, bem como identificar de que evento se trata, ou quais são suas caraterísticas (Gibson, 1966, p. 75). Mais uma vez, o que está em jogo é o corpo engajado em um ambiente e em uma experiência e, nesse sentido, de certa forma, o ouvir e o escutar acontecem simultaneamente. 
The auditory systems begins at the once to adjust to any imbalance of the stimulation. In the human auditor the head is turned automatically so as to nullify, for the pulses of sound following the first, the temporal priority and the intensive difference. If this is not immediately achieved, the system 'hunts' until the inputs to the two sides are symmetrical. The observe is then oriented to the source of sound, facing it whit all the sensory equipment of the head. He is in a position to look at the rolling stone, at the maker of the cry of distress, or at the speaker. [...] Both the orienting and adjusting responses of the auditory system, be it noted, are a circular feedback from the first input, modifying it in the direction of some optimum. Listening is what the system is for, hearing is incidental. (Gibson, 1966, p. 83)

Para Gibson, portanto, a função do sistema auditivo é a escuta mais do que o estimulo de ouvir - pois está vinculado ao movimento e a orientação. Retomando o mote que inicia esta parte do texto, essa abordagem de Gibson nos revela o sentido da afirmação de Ingold sobre "escutar no som". É "em meio ao som" que escutamos, obtemos informações de eventos e do ambiente, que nos orientamos no espaço e nos acontecimentos. Nesse sentido, diferente de uma antropologia dos sentidos, como é o caso da proposta de Bastos (1999; 1999b), a perspectiva aqui se remete mais a proposição ingoldiana de uma antropologia sensorial, na medida em que o sentido ou significado das sonoridades não está na maneira pela qual um sujeito escuta o ambiente, sendo, nesse caso, a escuta um atributo da cultura (ou seja, não se trata de uma "visão de mundo" que é orientada pela cultura ou sociedade). O sentido se dá na relação ecológica com o ambiente, não são atribuídos pelo ouvinte aos eventos. É importante considerar que não se trata de negar a produção de representações ou de dimensões simbólicas às sonoridades e à escuta, minha questão é não submeter a escuta como um fenômeno perceptivo - e que está articulada com outros sentidos - a estas representações. Retomando Feld e Gibson, o sentido das sonoridades e da escuta se dá nas presenças percebidas nas relações ecológicas, para todos os seres envolvidos na relação. A etnografia sonora, ou dos sons, de certa forma nos demanda uma consciência desse processo de escuta e, sobretudo, desse processo de 
orientação, pois se trata principalmente de seguir os sons e registrá-los em sua dinâmica de transformações da paisagem, como reveladores de eventos e acontecimentos. Escutar "em meio aos sons" não é apenas afirmar uma imersão na paisagem, mas uma forma de atenção, no caso da etnografia, para os ritmos, as intensidades, as vibrações e mudanças. É a partir dessa perspectiva que proponho pensar a etnografia sonora como transdução.

\section{Etnografia Sonora e Transdução}

Stefan Helmereich, a bordo do submarino Alvin, dedica-se a refletir sobre as sonoridades das práticas técnico-científicas, ou seja, como determinados sinais sonoros produzem o efeito de traduzir para os oceanógrafos que aí trabalham a paisagem subaquática que buscam analisar. Mas, para o autor, há algo mais aí que não apenas o reconhecimento de uma paisagem externa aos pesquisadores. Esses sons ou sinais produzem dados não só sobre o exterior do submarino, como também sobre o seu interior, na medida em que estão ligados ao conhecimento produzido sobre o oceano. É nessa condição de pesquisa e escuta que Helmreich aponta para uma etnografia sonora capaz de perceber - pela atenção à escuta, ao eco, às ressonâncias e reverberações - os sentidos de presença e distância que conformam os ambientes, ao mesmo tempo em que retoma a discussão de Feld sobre acustemologia para analisar as formas de conhecer dos oceanógrafos a bordo do Alvin. A pergunta do autor pode se traduzir em: Será que os sons apenas cercam a produção de conhecimento nos laboratórios, ou eles também estão ligados no conhecimento que é feito?

A questão que se coloca o autor é a de que o ambiente subaquático só se torna audível por meio de um processo de transdução, ou seja, de conversão de variações em um meio em variações correspondentes em outro meio (variações da energia mecânica das ondas sonoras na água para variações das ondas sonoras no ar, neste caso). Trata-se de um processo que altera a natureza ou o meio físico de um sinal para que este seja compreensível em outro meio, segundo o autor: "É preciso tradução técnica e cultural para esculpir uma paisagem sonora para os seres humanos fora do ambiente subaquático" (Helmreich, 2017, 
p. 182). Aplicando essa ideia a sua própria experiência etnográfica com oceanógrafos a bordo do Alvin, Helmreich compreende que esse seria o princípio de toda etnografia - transduzir informações, ou melhor, a etnografia seria o trabalho de transformar (ou converter) e processar significados de um meio para outro, da experiência vivida em campo para a escrita (ou, no caso deste texto, para outras formas narrativas como a sonora por exemplo).

Uma proposta transdutora para a etnografia, e, sobretudo, para uma etnografia sonora avança no sentido de uma atenção ao sensorial e à percepção, pois o argumento de Helmreich é o de que devemos duvidar da naturalização e do silêncio atribuído às sensações quando pensamos o trabalho de campo como "imersão", por exemplo. Segundo ele, a ideia de imersão tenderia a tornar invisível as dimensões sensoriais da pesquisa, uma dimensão essencial que informa sobre as diferentes formas de produção de conhecimento. Podemos comparar suas preocupações com a escuta, ou com o que chama de atos de sondar, com as descrições acima sobre os ritmos do trabalho na feira-livre ou a captura de peixes na praia da Barra da Lagoa em Florianópolis. Para o autor, os atos de sondar têm uma acepção importante de "se aprofundar", de investigar, que ele remete também à escuta. Assim, ouvir torna-se uma ação de direcionar " [...] nossos ouvidos para fora de nossa consciência habitual" (Helmreich, 2016, p. 196). Todas essas situações nos evidenciam processos de reconhecimento dos corpos e seus movimentos, dos saberes e práticas de cada um desses contextos, entre outros aspectos. Ainda como aponta Helmreich (2017, p. 199):

A transdução também me coloca em sintonia com os diversos tipos de corpos - estudantes, técnicos, pilotos submarinos, cientistas computacionais - que são todos parte da cadeia transdutora através da qual, para Delaney, o mar profundo se torna o oceano íntimo, imersivo.

Se, no interior do submarino, os corpos ali presentes estão engajados em uma ecologia de comunicação baseada em diferentes mídias e que, segundo o autor, orienta os sentidos dos pesquisadores, podemos pensar o mesmo para os processos de gravação e edição nas etnografias sonoras. Procuro entender os processos de gravação e edição 
de sonoridades como um processo técnico - continuo e nunca completo - que é o resultado de diversos desenvolvimentos associados a fazer aparecer, destacar as formas do espaço, as temporalidades, os ritmos, as práticas e as interações que podem ser narradas sonoramente. Não se trata, de forma nenhuma, de retratar o real, mas produzir efeitos de sensação, reapresentar os processos perceptivos de presenças e eventos ecológicos vividos em campo.

Assim, as mídias e as tecnologias intensificam ou incrementam nossos sentidos já que, ao menos no caso do registro sonoro, o microfone e o gravador nos permitem ouvir além daquilo que o ouvido normalmente alcança. Penso que o microfone e o gravador devem ser levados em conta tanto nas formas de seguir os acontecimentos em campo, como em suas potencialidades de participação nessa "cadeia transdutora", como aponta Helmreich. Isso significa questionar profundamente a ideia de registro como mero dado, ou mesmo como reprodução do real, sobretudo na medida em que em muitos momentos gravamos o que não necessariamente estaríamos ouvindo sem o equipamento, mas que são sinais das transformações da paisagem. O registro "faz" o dado e, sobretudo, transforma ou transduz as experiências de campo, permitindo de certa forma uma maior aproximação com essas experiências. A potência de pensar a etnografia como transdutora, me parece, está diretamente relacionada ao entendimento dessa conversão de sinais ou energias de um meio a outro, pois é essa conversão que nos permite colocar realidades de diferentes ordens em contato. Compreender a etnografia como transdução, para o caso do som, significa estar atento àquilo que escutamos e das diferenças entre escutar atentamente sem a mediação de um equipamento, escutar com esta mediação e ainda o resultado disso tanto na gravação como na posterior montagem de narrativas. É a partir dessa atenção que podemos operar de forma mais eficaz com as mídias que possibilitam uma etnografia sonora - microfone, gravador, fone de ouvido, etc. - e a partir delas seguir as diferenças, os ritmos, as ressonâncias e também, como aponta Helmreich, os ruídos, distorções, zumbidos e resistências, ao que é indesejável para os ouvidos. Enquanto gravamos estamos necessariamente operando uma transdução e não simplesmente 
capturando um dado da realidade a ser posteriormente analisado. Seguindo tanto Feld quanto Helmreich, estamos produzindo aí efeitos de presença e diferença que nos permitem contar as histórias em campo, mas também descobrir estas histórias. Assim, tanto os processos de gravação como de edição constituem-se como condições importantes de produção de sentido para a antropologia e etnografia.

Um dos aspectos fundamentais de uma proposta transdutora para a etnografia é justamente a atenção, tanto à materialidade do som como à participação das mídias de registro na produção da pesquisa. Aqui penso que essa proposição combina-se com aquela de W. Gaver a respeito da matriz auditiva: o som opera como um padrão de transformações na medida em que uma onda sonora se propaga no ar. Se a transdução é um processo de conversão de um sinal (ou de um padrão de diferenças), de um meio para um sinal em outro meio, é preciso ter atenção a esses padrões de mudança física (ou acústica) para seguir os ritmos e ressonâncias da paisagem e das diferentes ações que a compõem. Não se trata de prever para onde ou como uma onda sonora irá se propagar, mas de perceber por meio da escuta e do registro, como esses padrões de mudança informados pela matriz auditiva narram as paisagens, ações e percepções. A paisagem cujos sinais, cheiros e sons constituem uma ambiência específica, que ao mesmo tempo faz os seres que a habitam e é feita por eles (Ingold, 2000, p. 190) se apresenta em suas formas de transformação e temporalidade que podem ser registradas pelo engajamento microfone-gravador-pesquisador-ambiente. Segundo Ingold (2000, p. 192): "It is from this relational context of people's engagement with the world, in the business of dwelling, that each place draws its unique significance". A paisagem é uma experiência vivida.

Da mesma forma, essa escuta que resulta em gravações sonoras em campo é sempre mediada pelo equipamento de gravação e suas possibilidades. Aquilo que está registrado é um recorte temporal de uma situação ou evento que pode ser reelaborado por meio da montagem. O microfone, que como já afirmei antes é também um transdutor, converte esses sinais mecânicos das ondas sonoras em sinais elétricos que vão compor a paisagem sonora gravada. Uma vez que esses sons registrados passem pelo processo de edição e possam ser escutados 
em playback temos ainda uma nova conversão dos sinais elétricos em ondas mecânicas sonoras que se propagam no ar. Inevitavelmente a forma de conhecer passa pela mediação das tecnologias de gravação e reprodução.

Helmreich pondera que uma etnografia transdutora "[...] seria um modo de atenção que pergunta como as definições de sujeitos, objetos e campo emergem em relações materiais que não podem ser modeladas com antecedência" (Helmreich, 2017, p. 203). O que estamos falando aqui é do que pode ser descoberto em relação às diferentes sensibilidades que são experienciadas cotidianamente a partir de um engajamento etnográfico via gravação e edição. Não se trata, é claro, de processos idênticos - a gravação, mais errante, nos fala de um aprendizado junto com as pessoas, formas de tratar essas experiência sensorial que acontece no campo. A edição, por sua vez, navega pelas possibilidades de construir um relato que dê conta das diferentes presenças que são descobertas no trabalho de campo. Assim, uma etnografia transdutiva pode ser vista como um modo de atenção - como as definições de sujeitos, objetos e campo emergem nas relações materiais.

Se pensarmos em termos das múltiplas presenças, porque não tratar o microfone e o gravador, mais do que meras extensões do corpo do pesquisador, como efetuando outro corpo em seu acoplamento com o pesquisador, um corpo agora com capacidades que não tinha antes desse acoplamento? Que participa de forma ativa dos eventos que se desenrolam? Isso não significa "esconder" as decisões de posicionamento do pesquisador, pelo contrario, significa pensar que tais decisões podem ser tomadas a partir de uma perspectiva ecológica, na qual não só os humanos fazem coisas, mas também o vento, as ondas, os alimentos e utensílios fazem diferenças e transformações, proporcionando assim imagens outras que não aquelas que pressupõem um ponto de vista ou de escuta que revelaria as representações dos sujeitos sobre os fenómenos, mas que permite outras escutas. O que se escuta no som, portanto, é mais do que "um barulho de [...]", são padrões de movimento, repetições de gestos e socialidades que revelam num caso os ritmos do trabalho, as qualidades dos alimentos e das 
relações de troca nos mercados e, no outro, padrões de movimento que indicam a presença de eventos ecológicos (a corrida dos cardumes), e que fazem igualmente eventos ecológicos (o cerco ao cardume).

\section{Notas}

1 Gostaria de agradecer ao Rafael Devos pela parceria nas revisões e pelas sugestões que foram fundamentais para a finalização deste artigo. Agradeço ainda aos demais colegas do CANOA que ouviram apresentações preliminares deste debate e também fizeram contribuições importantes.

2 O microfone é um exemplo de transdutor, já que transforma energia mecânica sonora em um sinal elétrico. Já o alto-falante funciona de forma inversa ao microfone, convertendo sinais elétricos em energia sonora. O ouvido também pode ser pensado como um transdutor, pois recebe a energia sonora nas vibrações do ar, e essa energia é transformada em sinais elétricos no ouvido interno, que, por sua vez, são transmitidos pelo nervo até o cérebro.

3 As estruturas invariantes referem-se a informações que permanecem constantes, mesmo que o observador se movimente, diferente do que o autor chama de estrutura perspectiva que muda com o deslocamento. Um exemplo do primeiro caso seria o horizonte, que sempre vai identificar a separação entre chão e céu, já no caso das estruturas perspectivas o deslocamento pode fazer variar o tamanho de um objeto. Como sinaliza Reed "Perspective structures specify where we are heading, and invariant structures specify the nature of what we are heading toward" (Reed, 1989, p. 291).

4 Transito da primeira pessoa do singular para a primeira do plural ao me referir à experiência etnográfica, pois esta é uma pesquisa que foi realizada em equipe, na qual trabalhei com os colegas Rafael Victorino Devos e Gabriel Coutinho Barbosa. Assim, nos momentos de descrição geral a respeito da etnografia escrevo na primeira pessoa do plural. Como me concentrei, sobretudo, nos processos de registro e de edição de sons, quando me refiro a esses momentos passo então para a primeira pessoa do singular na escrita deste texto.

\section{Referências}

BASTOS, Rafael de Menezes. A Musicológica Kamayurá: para uma Antropologia da Comunicação no Alto Xingu. 2. ed. Florianópolis: Editora da UFSC, 1999a. $302 \mathrm{p}$

BASTOS, Rafael de Menezes. Apùap World Hearing: On the Kamayurá Phono-Auditory System and the Anthropological Concept of Culture.

World of Music, [S.l.], v. 41, n. 1, p. 85-96. $1999 \mathrm{~b}$. 
BATESON, Gregory. Critérios de sistemas mentais. In: BATESON, Gregory. Mente e Natureza. Rio de Janeiro: Francisco Alves, 1986. Cap. 4. p. 99138.

BATESON, Gregory. Form and Pattern in Anthropology. In: BATESON, Gregory. Steps to an ecology of mind. London: Jason Aronson Inc., 1987. Cap. 3. p. 63-125.

CHION, Michel. Le son: traité d'acoulogie. Paris: Armand Colin, 1998. 348 p.

DESHAYS, Daniel. Pour une écriture du son. Paris: Klincksieck, 2006. $190 \mathrm{p}$.

DEVOS, Rafael Victorino; BARBOSA, Gabriel Coutinho; VEDANA, Viviane. Paisagens como panoramas e ritmos audiovisuais: percepção ambiental na pesca da tainha. Gis: Gesto, Imagem e Som, São Paulo, v. 1, n. 1, p. 4158, jun. 2016. Semestral. Disponível em: < https://www.revistas.usp.br/gis/ article/view/1 16350>. Acesso em: 4 dez. 2017.

DEVOS, Rafael Victorino; BARBOSA, Gabriel Coutinho; VEDANA, Viviane. La production du paysage: pratiques de pêcheurs en bord de mer (Santa Catarina, Brésil). Études Rurales, Paris, v. 196, p. 57-72, jul./dez. 2015. Semestral.

FELD, Steven; SILVA, Rita de Cácia Oenning da. Sons e sentidos: entrevista com Steven Feld. Revista de Antropologia, São Paulo, v. 58, n. 1, p. 439468, 2015.

FELD, Steven; BRENNEIS, Donald. Doing anthropology in sound.

American Ethnologist, University of California, v. 31, n. 4, p. 461-474, nov. 2004.

FELD, Steven. Waterfalls of song: an acoustemology of place resounding in Bosavi, Papua New Guinea. In: FELD, Steven; BASSO, Keith. Senses of Place. Santa Fé/new Mexico: School Of American Research Press, 1996. Cap. 3. p. 91-136.

FONSECA, Sérgio Teixeira da et al. Abordagem ecológica à percepção e ação: fundamentação para o comportamento motor. Brazilian Journal of Motor Behavior, [S.l.], v. 2, n. 1, p. 1-10, 2007.

GAVER, William W.. What in the world do we hear?: An ecological approach to auditory event perception. Ecological Psychology, [S.l.], v. 1, n. 5, p. 1-29, 1993.

GIBSON, James. The Ecological Approach to Visual Perception. Boston: MA: Houghton Mifflin., 1979. 332 p. 
GIBSON, James. The senses considered as perceptual systems. Boston: Ma: Houghton Mifflin., 1966. 335 p.

HELMREICH, Stefan. Um antropólogo debaixo d'água: Paisagens Sonoras Imersivas, Ciborgues Submarinos e Etnografia Transdutora. Caderno Eletrônico de Ciências Sociais, Vitória, v. 3, n. 1, p. 174-214, 31 mar. 2016. Disponível em: <http://periodicos.ufes.br/cadecs/issue/view/646/ showToc $>$. Acesso em: 16 jun. 2017.

INGOLD, Tim. Making: anthropology, archaeology, art and architecture. New York: Routledge, 2013. 163 p.

INGOLD, Tim. Trazendo coisas de volta à vida: emaranhados criativos num mundo de materiais. Horizontes Antropológicos, Porto Alegre, v. 18, n. 37, p. 25-44, jan.-jun. 2012. Semestral.

INGOLD, Tim. Being Alive: Essays on Movement, Knowledge and Description. London: Routledge, 2011. 270 p.

INGOLD, Tim. Da transmissão de representações à educação da atenção. Educação, Porto Alegre, v. 33, n. 1, p. 6-25, jan.-abr. 2010.

INGOLD, Tim. Pare, Olhe, Escute! Visão, Audição e Movimento Humano, Ponto Urbe [Online], 3 | 2008, posto online no dia 31 julho 2008. Disponível em: <http://pontourbe.revues.org/1925>. Acesso em: 30 set. 2016.

INGOLD, Tim. The Perception of the Environment: Essays on Livelihood, Dwelling and Skill. London: Routledge, 2000. 465 p.

REED, Edward S. James J. Gibson and the Psychology of Perception. New Haven Adn London: Yale University Press, 1989. 384 p.

VEDANA, Viviane. Técnicas corporais e ritmos do trabalho nos mercados de rua: um ensaio sobre a relação entre gestos corporais e atos de fala. In: ZANINI, Maria Catarina Chitolina; SANTOS, Miriam de Oliveira. Feiras, feirinhas e feirões: a "economia dos centavos" em foco. São Leopoldo: Oikos, 2017. Cap. 3. p. 40-58.

VEDANA, Viviane. Fazer a feira e ser feirante: a construção cotidiana do trabalho em mercados de rua no contexto urbano. Horizontes Antropológicos, Porto Alegre, v. 19, p.41-68, jan.-jun. 2013. Semestral. Disponível em: < http://www.scielo.br/pdf/ha/v19n39/v19n39a03.pdf>. Acesso em: 12 jan. 2018.

VEDANA, Viviane. Diálogos entre a imagem visual e a imagem sonora: a experiência de escritura do sonoro nos documentários etnográficos.

Ciberlegenda: Revista do Programa de Pós-graduação em Cinema e Audiovisual da Universidade Federal Fluminense, Niterói, v. 1, n. 24, p.29-42, jul.-dez. 2011. 
VEDANA, Viviane. No mercado tem tudo que a boca come: estudo Antropológico da duração das práticas cotidianas de mercado de rua no mundo urbano contemporâneo. 2008. 255 f. Tese (Doutorado) - Curso de Pós-graduação em Antropologia Social, Universidade Federal do Rio Grande do Sul, Porto Alegre, 2008. Disponível em: < http://hdl.handle. net/10183/13383 >. Acesso em: 29 nov. 2017.

Recebido em 24/03/2018

Aceito em 30/04/2018 